\title{
Heterogeneous vesiculation of 2011 EI Hierro xeno-pumice revealed by $X$-ray computed microtomography
}

\author{
S. E. Berg ${ }^{1}$ - V. R. Troll ${ }^{1,2}$ - F. M. Deegan ${ }^{1} \cdot$ S. Burchardt ${ }^{1}$ - M. Krumbholz ${ }^{1,3}$. \\ L. Mancini ${ }^{4}$ - M. Polacci $^{5}$ • J. C. Carracedo ${ }^{2}$ - V. Soler ${ }^{6}$ - F. Arzilli ${ }^{4,5}$ • F. Brun ${ }^{4,7}$
}

Received: 19 June 2016 / Accepted: 8 October 2016/Published online: 14 November 2016

(C) The Author(s) 2016. This article is published with open access at Springerlink.com

\begin{abstract}
During the first week of the 2011 El Hierro submarine eruption, abundant light-coloured pumiceous, high-silica volcanic bombs coated in dark basanite were found floating on the sea. The composition of the light-coloured frothy material ('xeno-pumice') is akin to that of sedimentary rocks from the region, but the textures resemble felsic magmatic pumice, leaving their exact mode of formation unclear. To help decipher their origin, we investigated representative El Hierro xeno-pumice samples using X-ray computed microtomography for their internal vesicle shapes, volumes, and bulk porosity, as well as for the spatial arrangement and size distributions of vesicles in three dimensions (3D). We find a wide range of vesicle morphologies, which are especially variable around small fragments of rock contained in the xeno-pumice samples. Notably, these rock fragments are almost exclusively of sedimentary origin, and we therefore interpret them as relicts an the original sedimentary ocean crust protolith(s). The irregular vesiculation textures observed probably resulted from pulsatory release of volatiles from multiple
\end{abstract}

Editorial responsibility: J.E. Gardner

Electronic supplementary material The online version of this article (doi:10.1007/s00445-016-1080-x) contains supplementary material, which is available to authorized users.

S. E. Berg

e.sylviaberg@gmail.com

1 Department of Earth Sciences, Centre for Experimental Mineralogy, Petrology and Geochemistry (CEMPEG), Uppsala University, Villavägen 16, 75236 Uppsala, Sweden

2 GEOVOL, Universidad de Las Palmas de Gran Canaria, Las Palmas de Gran Canaria, Spain

3 Geoscience Centre, Georg-August-University of Göttingen, Goldschmidtstrasse 1-3, 37077 Göttingen, Germany sources during xeno-pumice formation, most likely by successive release of pore water and mineral water during incremental heating and decompression of the sedimentary protoliths.

Keywords ElHierro $\cdot$ Xeno-pumice $\cdot$ X-CTimaging $\cdot$ Vesicle morphologies $\cdot$ Vesicle size distribution $\cdot$ Heterogeneous vesiculation $\cdot$ Sedimentary ocean crust

\section{Introduction}

\section{The El Hierro 2011-2012 eruption}

El Hierro is the westernmost and the youngest of the seven Canary Islands (1.2 Ma, Guillou et al. 1996), which are widely attributed to an underlying mantle plume (e.g. Carracedo et al. 2001; Geldmacher et al. 2005; Zaczek et al. 2015). No historic volcanic activity was known on El Hierro before a submarine eruption commenced on October 10, 2011, off the southern

4 Elettra-Sincrotrone Trieste, S.C.p.A., S. S. 14-km 163,5 in AREA Science Park, 34149 Basovizza (Trieste), Italy

5 School of Earth and Environmental Sciences, University of Manchester, Williamson Building, Oxford Road, Manchester M13 9PL, UK

6 Estación Vulcanológia de Canarias, CSIC, Avda. Astr. Fco. Sánchez 3, 38206 La Laguna, Tenerife, Spain

7 Department of Engineering and Architecture, University of Trieste, Via A. Valerio, 10, 34127 Trieste, Italy 
coast. Seismic unrest began several months before the eruption and was associated with vertical and lateral magma movement. Volcanic activity continued for several months but remained submarine for the entire eruption period until activity finally ceased in March 2012 (e.g. Carracedo et al. 2012a, b, 2015; Gonzales et al. 2013). Surface expressions of the eruption included green discolouration of seawater, together with intense bubbling and degassing, and the presence of two distinct types of floating lava bombs during separate stages of the eruption. During the first week of the eruption, abundant light-coloured pumiceous bombs, enclosed by a basanite coating were floating on the sea ('xeno-pumice'), whereas entirely basanitic 'lava balloons', usually with hollow interiors, occurred throughout the entire eruption (Figs. 1 and 2, e.g. Kueppers et al. 2012; Meletlidis et al. 2012; Perez-Torrado et al. 2012; Troll et al. 2012).

\section{El Hierro xeno-pumice and its composition}

The 2011 to 2012 El Hierro submarine eruption emitted lightcoloured, high-silica, pumiceous bombs (xeno-pumice) during the first week of eruptive activity. The xeno-pumice phenomenon was the source of considerable controversy at the time, and the origin of these peculiar samples is still debated (see Carracedo et al. 2012a, 2015; Meletlidis et al. 2012; Perez-Torrado et al. 2012; Troll et al. 2012, 2015; Schmincke and Sumita 2013; Sigmarsson et al. 2013; Del Moro et al. 2015; Rodriguez-Losada et al. 2015; Zaczek et al. 2015). The debate focuses on whether the white and essentially crystal-free xeno-pumice represent either (1) high-silica magma or altered magmatic rocks that vesiculated during contact with hot basanite magma of the El Hierro eruption (e.g. Meletlidis et al. 2012; Sigmarsson et al. 2013; Del Moro et al. 2015), or (2) recycled sedimentary rocks that degassed during heating and transport while entrained in the ascending basanite magma (e.g. Troll et al. 2012; Schmincke and Sumita 2013; Rodriguez-Losada et al. 2015; Zaczek et al. 2015).

The xeno-pumice samples that erupted offshore El Hierro in 2011 exhibit intense mingling and mixing between the enclosing basanite carapace and the white to grey pumiceous cores. The cores contain partly intact sedimentary relicts but lack distinctly igneous fragments or igneous mineralogy
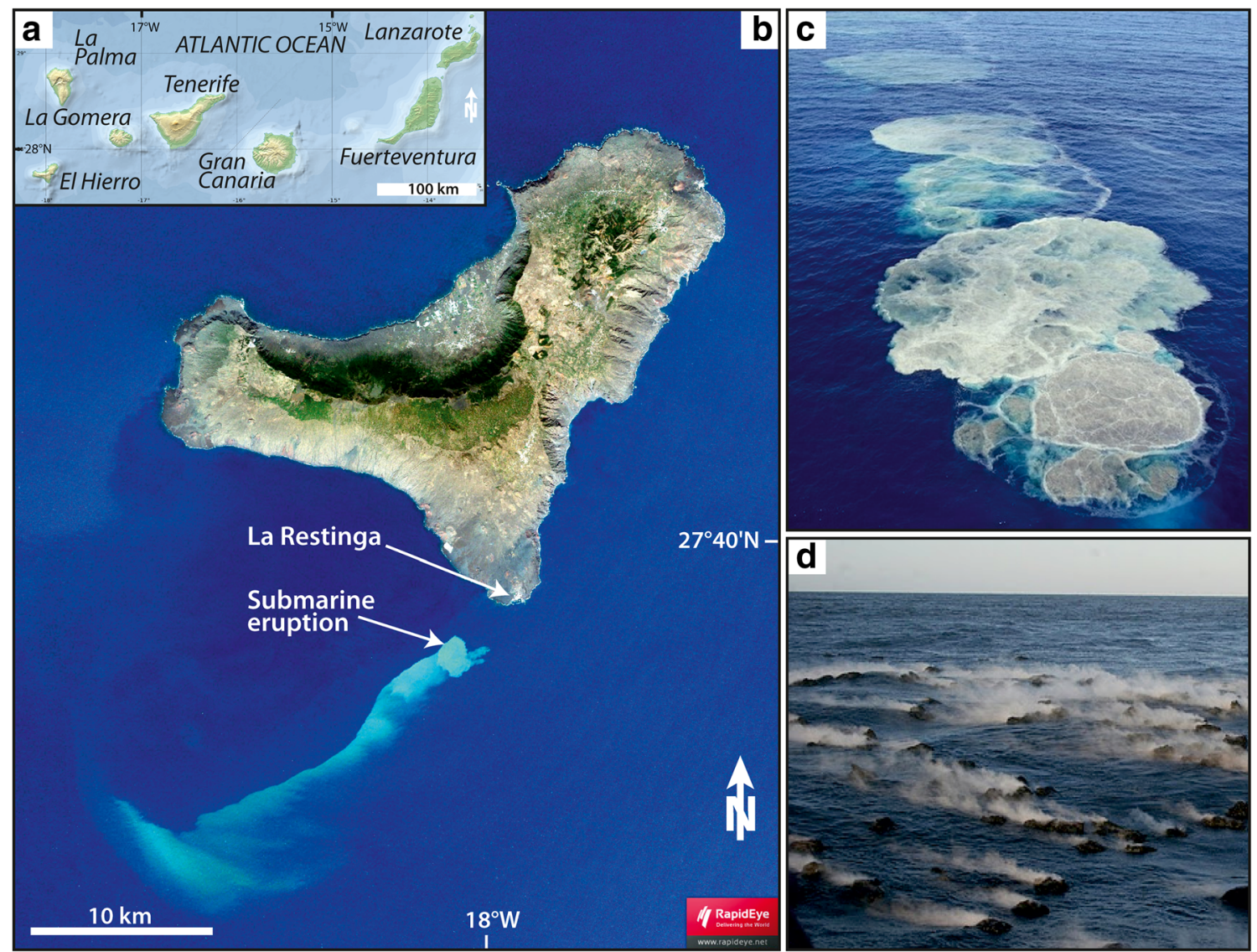

Fig. 1 a Topographic map of the Canary Islands off the coast of northwestern Africa (courtesy of Wikimedia Commons). El Hierro is the youngest and westernmost island in the archipelago. b True colour RapidEye satellite image of El Hierro island, captured by the Moderate Resolution Imaging Spectroradiometer (MODIS) aboard the Terra

satellite on December 21, 2011. The stain on the ocean caused by the submarine eruption can be seen SSE of El Hierro (image courtesy of NASA GSFC). $\mathbf{c}$ Close-up of the discolouration of seawater and $\mathbf{d}$ the floating lava balloons and frothy xenoliths that emerged at the surface during the eruption (Carracedo et al. 2012a, b) 

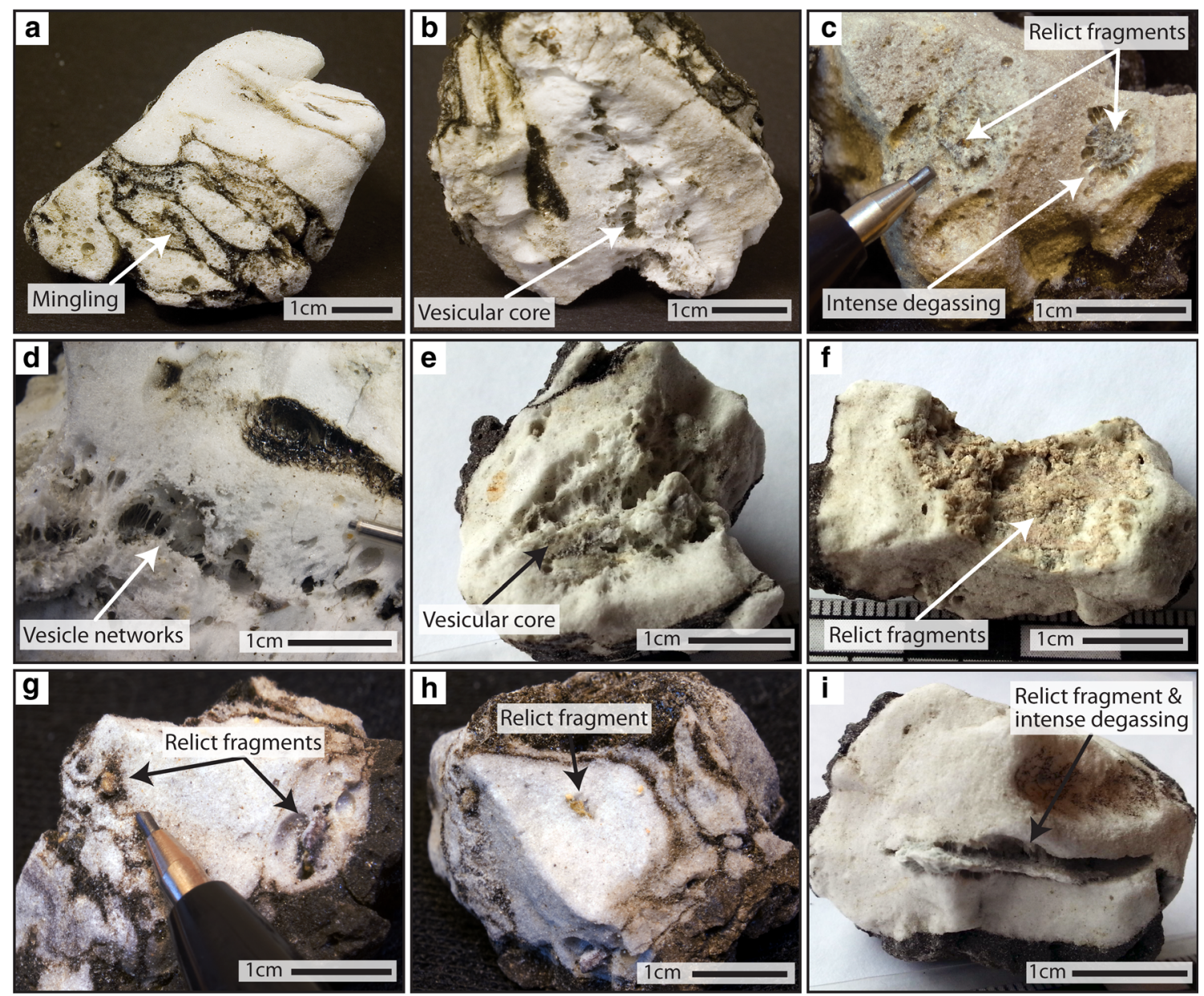

Fig. 2 a-i A selection of xeno-pumice hand specimens that were erupted during the early days of the 2011 El Hierro eruption. Xeno-pumice show a variety of vesicle sizes and shapes, mingling textures between white pumiceous cores and basanite lava rims, highly vesiculated core regions,

interconnected vesicle networks, relict sedimentary fragments, as well as intense degassing textures around xenocrystals and crustal restite fragments

(Fig. 2, Meletlidis et al. 2012; Troll et al. 2012; Zaczek et al. 2015). X-ray diffraction (XRD) analyses of the lightcoloured cores of xeno-pumice revealed a mineralogy similar to that of sedimentary rock assemblages in the region, comprising quartz, clays, jasper, carbonate and a range of contact metamorphic minerals, while igneous minerals were notably absent in the XRD determinations (Troll et al. 2012; Rodriguez-Losada et al. 2015). Geochemical analyses of xeno-pumice (e.g. Meletlidis et al. 2012; Troll et al. 2012; Martí et al. 2013; Sigmarsson et al. 2013; Carracedo et al. 2015; Del Moro et al. 2015; RodriguezLosada et al. 2015) show that they have high silica contents $\left(\mathrm{SiO}_{2}=68-71\right.$ wt.\%) and trace element compositions that differ significantly from known El Hierro magmatic rocks, including an unusual enrichment in uranium in many xeno-pumice samples (cf. Carracedo et al. 2015; Rodriguez-Losada et al. 2015).

In addition, ${ }^{87} \mathrm{Sr} /{ }^{86} \mathrm{Sr}$ ratios are elevated in xeno-pumice (0.706426 to 0.710134 , Del Moro et al. 2015) and overlap with regional sedimentary rocks, while ${ }^{143} \mathrm{Nd} /{ }^{144} \mathrm{Nd}$ ratios in xeno-pumice (0.512905 to 0.512978 , Del Moro et al. 2015) are consistent with magmatic values from the Canary Islands. However, Nd concentrations of xeno-pumice are considerably lower than those of El Hierro basanite rocks, despite the fact that regular magmatic fractionation from basanite to trachyte and eventually rhyolite would be expected to cause Nd enrichment in evolved residual melts. El Hierro xeno-pumice samples show $\mathrm{Nd}$ concentrations of $\sim 20-60 \mathrm{ppm}$, while the 2011 El Hierro basanites have $\mathrm{Nd} \sim 53-70 \mathrm{ppm}$. Rhyolites from other Canary Islands have $\mathrm{Nd}$ concentrations of $\sim 70$ $125 \mathrm{ppm}$, which exceed the Nd concentration in El Hierro basanite and xeno-pumice (e.g. Troll and Schmincke 2002; Troll et al. 2012). Indeed, El Hierro xeno-pumice samples fall on a mixing line between El Hierro basanite and local siliciclastic sediments ( $\mathrm{Nd}=1$ to $25 \mathrm{ppm}$, e.g. von $\mathrm{Rad}$ and Einsele 1980), which implies that a low Nd sedimentary melt would be highly susceptible to uptake of Nd from a surrounding basanite magma. The ${ }^{143} \mathrm{Nd} /{ }^{144} \mathrm{Nd}$ ratios of El Hierro xeno-pumice were hence conceivably compromised while in contact with their host basanite. Thus, the Sr isotopes require a 
high sedimentary input, while $\mathrm{Nd}$ isotopes are probably a less robust tracer due to the low concentrations of $\mathrm{Nd}$ in the sedimentary protoliths and the potential for overprint from the basanite host. Notably, oxygen isotope ratios of El Hierro xeno-pumice also differ markedly from mantle values and are similar to values found in S-type felsic magmas and sedimentary rocks and thus support the $\mathrm{Sr}$ isotope evidence for a crustal origin (e.g. Savin and Epstein 1970; Troll et al. 2012; RodriguezLosada et al. 2015). Since oxygen is a major element in magma and in siliciclastic sedimentary rocks (ca. $50 \mathrm{wt} \%$ ), while rare earth elements like $\mathrm{Nd}$ are present in trace quantities only, it is more difficult to significantly change the oxygen isotope ratio by minor contamination processes. Oxygen isotopes in tandem with the mineralogical and $\mathrm{Sr}$ isotope evidence above thus support a sedimentary rock origin for El Hierro xeno-pumice.

\section{Xeno-pumice textures and vesicularity}

The 2011 El Hierro xeno-pumice samples are highly porous, which allowed them to float on water like magmatic pumice (e.g. Carracedo et al. 2012a). Upon contact with seawater, El Hierro xeno-pumice solidified and preserved frozen snapshots of their degassing history. Because vesicle size, shape and number density in xeno-pumice are ultimately a function of (i) the volatile content of the source material and (ii) the physical conditions the material was exposed to, the vesicle textures observed in the individual samples can probably offer insight into evolutionary processes during xeno-pumice formation and vesiculation (cf. Song et al. 2001; Polacci et al. 2008, 2009). From thin section analyses Meletlidis et al. (2012) and Sigmarsson et al. (2013) found that the xenopumice cores and the basanitic crust are unimodally vesiculated, which they suggest to be a result of a single vesicle nucleation event in an aphyric magma. These authors argue that crystal-poor, compositionally homogeneous felsic magma (or hydrothermally altered aphyric igneous rock) frothed up in a single pulse when brought in contact with mafic basanite magma (Meletlidis et al. 2012; Sigmarsson et al. 2013). In contrast, a study of more than 300 samples by Troll et al. (2012), Carracedo et al. (2015) and Zaczek et al. (2015) show a heterogeneous spatial distribution of vesicle sizes within each individual specimen, with particularly intense vesiculation around sedimentary relicts (Fig. 2). These relicts were found to contain fossils of Cretaceous to Pliocene age (Zaczek et al. 2015), which document a wide temporal range of sedimentation and imply a range of sedimentary protolith compositions to be present beneath El Hierro. Different sedimentary facies would likely display a variety of melting and vesiculation points amongst samples when heated, but also within individual samples due to variable pore water contents and proportions of anhydrous and hydrous phases present in a single portion of a sedimentary protolith (cf. Robertson and Stillman 1979a, b; Gluyas and Cade 1997; Steiner et al. 1998).
Indeed, if the 2011 El Hierro xeno-pumice material is derived from sedimentary rock, they would be expected to display an irregular vesicle size distribution that varies spatially within and amongst samples. Up to now, our understanding of the vesiculation behaviour of El Hierro xeno-pumice remains limited because existing studies are exclusively based on $2 \mathrm{D}$ analyses as described above. In this paper, we provide computed X-ray microtomography (micro-XCT) data to resolve the three-dimensional (3D) spectrum of vesicularities present in El Hierro xeno-pumice and shed new light on its origin.

\section{Methods}

\section{X-ray microtomography}

From a sample suite of $>300$ xeno-pumice specimens collected during the early days of the El Hierro eruption in 2011 (Troll et al. 2012), we selected six specimens that broadly reflect the diversity seen in the overall sample suite. Xenopumice samples were cut into $10 \times 10 \times 10 \mathrm{~mm}$ cubes and were analysed by micro-XCT at the SYRMEP beamline (Tromba et al. 2010) and at the TomoLab station (Zandomeneghi et al. 2010) of the Elettra synchrotron light laboratory in Basovizza (Trieste, Italy), in November/ December 2011 and September 2012. Three out of the six samples were scanned using a monochromatic, nearlyparallel synchrotron X-ray beam in phase-contrast mode (edge-detection regime, Cloetens et al. 1996). The experimental parameters employed for the micro-XCT scan acquisitions are reported in Supplementary Table 1. A 12-bit, water-cooled CCD camera with an effective pixel size of $9 \times 9 \mu \mathrm{m}$ and $12 \mathrm{~mm} \times 18 \mathrm{~mm}$ field of view was used as detector. The collected radiographs were reconstructed into twodimensional (2D) axial slices with an isotropic voxel size (3D pixel) of $9.0 \mu \mathrm{m}$, using the custom-developed software Syrmep_tomo project 4.0 (Montanari 2003) and selecting the filtered back-projection algorithm for slice reconstruction (e.g. Kak and Slaney 1988).

The remaining three specimens were analysed using a microfocus X-ray source at the TomoLab station of Elettra (see Supplementary Table 1; Zandomeneghi et al. 2010). The TomoLab instrument provides a polychromatic X-ray beam with a cone beam geometry. The experimental parameters employed for the TomoLab station are reported in Supplementary Table 1. A 12-bit, water-cooled CCD camera with an effective pixel size of $12.5 \times 12.5 \mu \mathrm{m}$ and a maximum field of view of $50 \mathrm{~mm} \times 33 \mathrm{~mm}$ was used as detector. Depending on the instrument settings, the isotropic voxel size used for the XCT scans ranged from 5.0 to $7.1 \mu \mathrm{m}$. The analyses were performed under phase-contrast conditions, but with a lower contrast compared to the synchrotron radiation analyses. Reconstruction of 2D slices from the X-ray 
projections was performed by the commercial software COBRA (Exxim, USA), which is based on the FDK algorithm (Feldkamp et al. 1984). For further methodological details of the experimental setup and of the reconstruction procedure, see Ketcham and Carlson (2001) and Polacci et al. (2006, 2010).

\section{Vesicle analyses of EI Hierro xeno-pumice}

For all samples, the reconstructed 2D images were stacked, converted to 8-bit raw format and cropped using the freeware ImageJ (Abramoff et al. 2004). Volume renderings were obtained with the commercial software VGStudio MAX 2.0 (Volume Graphics). The rendered volumes were processed (3D filtering and segmentation) and analysed morphologically (sample porosity and skeletonization) using the Pore $3 D$ software library developed at Elettra (Brun et al. 2010; Zandomeneghi et al. 2010).

For each of the scanned samples, we made qualitative textural observations by examining the complete $2 \mathrm{D}$ image sequence (stack) and the 3D representations that were reconstructed using the whole data range (see Supplementary Table 2). Further processing of the micro-XCT digital dataset to extract vesicle volumes for quantitative image analyses in $3 \mathrm{D}$ involves the extraction of a volume of interest (VOI) with dimensions suitable for the available computing resources but preserving sample representativeness. Based on textural observations, VOIs were selected for each sample to visualise the main vesicle textures. To ensure that the analysed VOIs are representative elementary volumes (REV), we tested the convergence of porosity data from multiple VOIs of variable sizes within each sample (see Supplementary Table 2). Potential cutting effects from sample preparation and artefacts of the cone-beam reconstruction were avoided by selecting VOIs in the central parts of the imaged volumes.

To extract objects or phases for morphological analyses, the next step is image segmentation, which produces binary images optimised for the phases of interest. Vesicles were segmented in the 3D domain (by Pore $3 D$ ) using manual greyscale thresholding based on the greyscale histogram of the selected VOI and visual inspection of the slices in different directions, which allowed high sensitivity to the presence of noise and artefacts and proved favourable for our purpose compared to automatic thresholding algorithms. The threshold values were carefully selected iteratively for each individual sample. To avoid biasing from texturally complicated micro$\mathrm{XCT}$ images, pre- and post-segmentation smoothening filters were required on occasion to ease or refine the segmentation procedure (see Supplementary Table 2, cf. Polacci et al. 2006; Brun 2012). The 3D anisotropic diffusion filter was applied by the Pore $3 D$ software to smooth the greyscale input images prior to segmentation, while preserving object edges (cf. Perona and Malik 1990). When required, the binary images were treated further by removal of image noise from isolated clusters of connected object voxels, i.e. 'voxel islands' that are below a specified threshold value, which was individually determined for each sample (cf. Soille 2004). The procedure described above is summarised in Supplementary Fig. 1.

To quantify and graphically represent the degree of pore interconnection in El Hierro xeno-pumice, we adopted the gradient vector flow (GVF) skeletonization algorithm in Pore $3 D$ (cf. Brun and Dreossi 2010). For our samples, we favoured the GVF algorithm over other methods because it produces a thin and centred curve-skeleton even in the presence of noisy objects (i.e. voxel islands), which can occur in densely vesiculated samples. The skeleton is a graph of nodes and branches that represents an idealised spine running along the medial axis of a connected pore space (Lindquist and Lee 1996). Each single vesicle within the connected pore volume represents a skeleton node, and the branches represent gas pathways between them. Skeleton analysis allows us to quantify the number and the dimensions of nodes and branches, which determine the pore coordination number (i.e. the number of near neighbours to a central pore) and thus serves as characterisation of pore space interconnectivity. Pore thickness is measured via the concept of the maximal inscribed sphere (cf. Hildebrand and Rüegsegger 1997; Baker et al. 2012). This concept is based on the inflation of a sphere centred at a skeleton node, where the inflation continues until the sphere 'touches' the walls of the pore. Hence, the diameter of the maximally inflated sphere gives an idealised but representative minimum estimation of the pore size and thus vesicle size distributions prior to pore interconnection. We used this approach to analyse vesicle size distributions (VSDs).

\section{Results}

Xeno-pumice samples show total porosities from 63 to 75 vol. $\%$, which were calculated from the segmented volume of voxels attributed to the 'intra-vesicle' phase (pore space) relative to the total volume in the considered VOI (Supplementary Table 2). The image descriptor labelling of connected components in the Pore $3 D$ software is a measure of vesicle interconnectivity and shows that the xeno-pumice vesicles are dominantly interconnected and form a coherent volume. While the resolution limits of the method may have prevented recognition of very thin bubble walls, a small fraction of vesicles appear to be clearly isolated and the closed porosities within the analysed VOIs equal about $0.01 \mathrm{vol} . \%$, which equates to on average one isolated vesicle per $2 \mathrm{~mm}^{3}$ in our specimens (see Supplementary Fig. 2 and Supplementary Table 2). Petrographic observations, however, reveal vesicle walls of all sizes, and it is therefore likely that the volume of isolated vesicles is somewhat underrepresented as a result of 
the spatial resolution of the method. Textural observations of xeno-pumice in hand specimen and 3D reconstructions reveal that the isolated vesicles represent an estimated $1-2 \%$ of the total volume, which may be more representative overall than the low values derived from Pore $3 D$ (see Supplementary Fig. 2).

Individual vesicles in the analysed xeno-pumice samples are spherical to elongated and occasionally tortuous in shape, and range up to $1.4 \mathrm{~mm}$ in diameter (Fig. 3). From our 3D observations, we distinguish three general vesicle diameter groups $(\mathrm{V}): \mathrm{V}_{\text {small }}<100 \mu \mathrm{m}, \mathrm{V}_{\text {medium }} 100-300 \mu \mathrm{m}$, and $\mathrm{V}_{\text {large }}>300 \mu \mathrm{m}$. The number density $(n)$ of vesicles in each size group varies broadly following $n_{\text {large }}<n_{\text {medium }}<n_{\text {small }}$, but the abundance of vesicles within each size group varies between samples. For instance, $V_{\text {small }}$ is larger and $V_{\text {large }}$ is smaller in EH-XP-1 and EH-XP-13 than in the other three samples. We also find that high porosity samples are dominated by sub-spherical vesicles throughout all size classes (see samples EH-XP-2, EH-XP-10 and EH-XP-10LA; Fig. 3), while tortuously shaped small-sized vesicles become more frequent in the less porous samples (porosity $<65 \%$, see samples EH-XP-1 and EH-XP-13; Fig. 3). Spherical to subspherical vesicles are dominant, however, especially within the larger size fractions $\left(\mathrm{V}_{\text {medium }}\right.$ and $\left.\mathrm{V}_{\text {large }}\right)$, while the smallest vesicles are more distorted in places (see $\mathrm{V}_{\text {small }}$ in EH-XP-1 and EH-XP-13; Fig. 3a, c). Moreover, vesicles coexist with relict mineral fragments in most of the samples and the fragments are then typically observed to display a corona of particularly large sub-spherical vesicles (Fig. 3b, g, h, cf. Carracedo et al. 2015; Zaczek et al. 2015).

Coalescence and near-coalescence of vesicle pairs are observed in all of the samples, which is represented by subspherical to elongated and polylobate vesicle shapes. We note that neighbouring vesicle pairs, which are separated by a thin glass film only, commonly show either flattened or convex/ concave vesicle walls (Fig. 3c, f, h). Moreover, we observe wrinkled as well as ruptured vesicle walls, and plateau borders (i.e. thin glass channels created at the vertex point of three
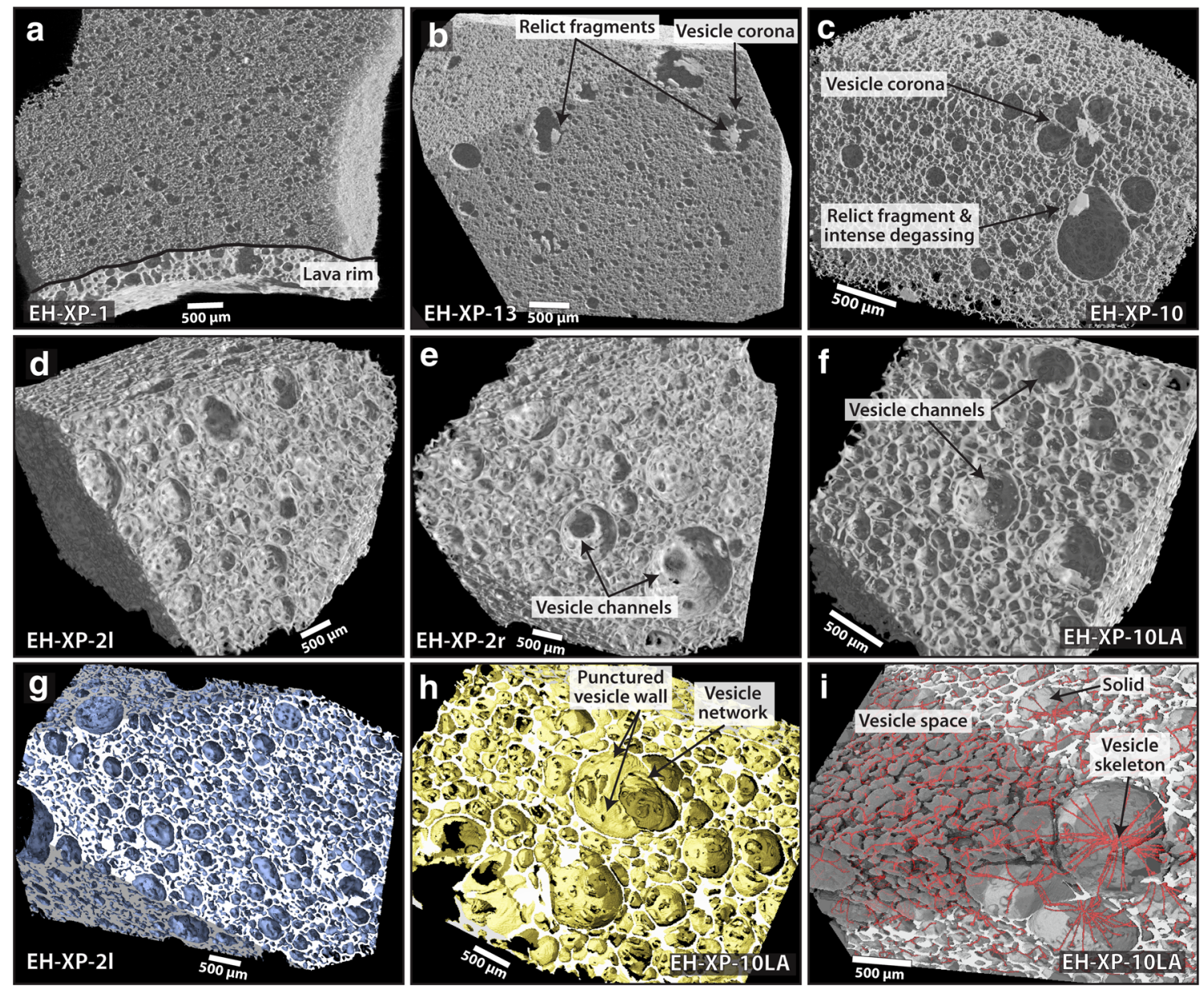

Fig. 3 a-i Three-dimensional micro-XCT renderings of El Hierro xenopumice. All xeno-pumice reconstructions show cut surfaces that represent an interior part of xeno-pumice. Scale bar is $500 \mu \mathrm{m}$ throughout. The solid phase is shown in grey (a-f), blue (g), yellow (h) or white (i). The outer lava rim is included in a (see bottom). Note the vesicle coronas around relict crustal fragments in e.g. b and $\mathbf{c}$, as well as large vesicle channels in $\mathbf{e}$ and $\mathbf{f}$. In $\mathbf{i}$, the vesicle space (gas phase) is presented as a semi-transparent grey overlay on top of the solid phase (white) and is shown with vesicle skeletons (red lines) that also visualise the connected gas pathways. Note the intense vesicle networking in $\mathbf{h}$ and $\mathbf{i}$ 
neighbouring vesicles during close packing, cf. Mangan and Cashman 1996, Fig. 3c, h). Indeed, the dominant fraction of vesicles in El Hierro xeno-pumice has preserved sub-spherical shapes but frequently shows punctured vesicle walls, consistent with petrographic observations (Fig. 3d-f, i, e.g. Troll et al. 2012; Carracedo et al. 2015). The computed vesicle skeletons run through these narrow apertures (Fig. 3i), which appear to function as gas pathways into the neighbouring vesicles and thus give rise to a continuous network of open porosity and as such the development of rock permeability. The number of skeleton branches that converge at the centre of each vesicle, hence approximating the number of gas channels that flow into or from each vesicle, is represented by the skeleton coordination number. The calculated mean coordination numbers of the vesicle skeleton in each sample range from 3.4 to 5.3 (see Fig. $3 \mathrm{i}$ and Supplementary Table 2).

Xeno-pumice VSDs were analysed using maximal inscribed sphere measurements that were produced from the skeleton analyses (Supplementary Table 2). For optimal comparability between different samples and to minimise artefacts caused by binning, the data were plotted using probability density functions (PDFs, Fig. 4). All samples show right skewed vesicle size distributions, with (main) modes between 0.06 and $0.08 \mathrm{~mm}$. The tails exhibit irregularities, i.e. increases in vesicle number over a given diameter range, that

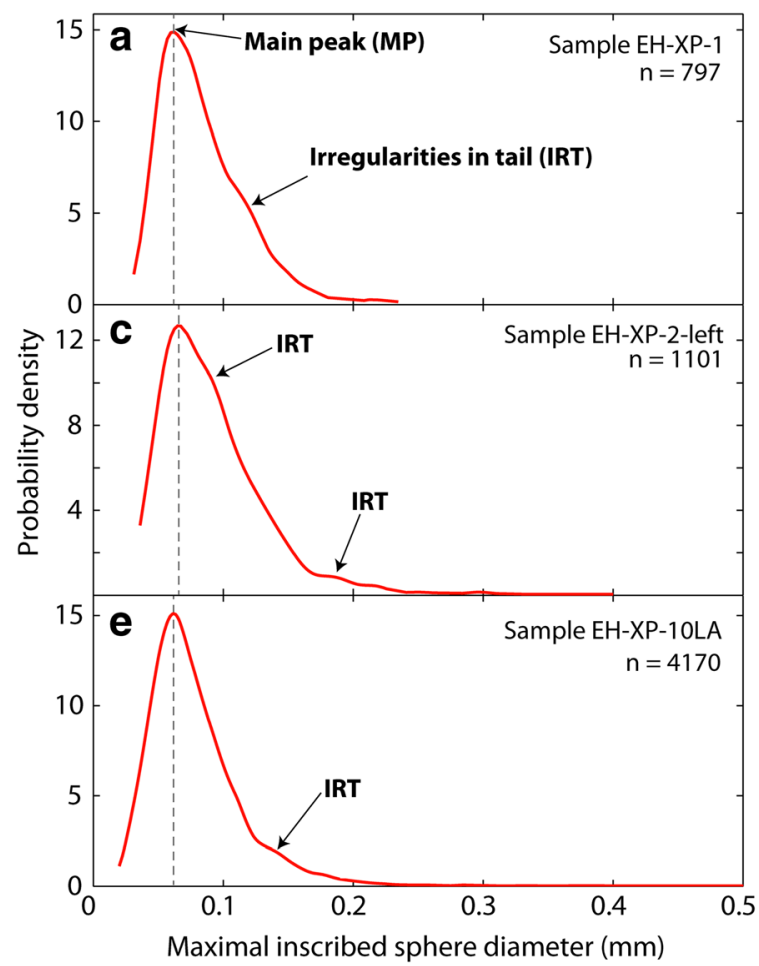

Fig. 4 a-f Vesicle size distributions (VSDs) of the analysed El Hierro xeno-pumice specimens plotted using probability density functions, where the $Y$-axis shows probability density and the $X$-axis shows vesicle diameter $(\mathrm{mm})$. Vesicles in all samples have their mode at about $0.07 \mathrm{~mm}$ (main peak (MP)), and the VSD curves are skewed to the right, with dominantly occur at bubble diameters between 0.1 and $0.2 \mathrm{~mm}$, and which are interpreted to reflect multiple minor modes within the bubble size distributions (Fig. 4). Because the diameters at which we observed the main modes are about one order of magnitude above the detectability limit of structures in the 3D images, and because of the automated sampling procedure applied, we note that our data are unlikely to reflect resolution or sampling artefacts (cf. Degruyter et al. 2010; Giachetti et al. 2011).

\section{Discussion}

The appearance of floating xeno-pumice rocks during the initial phase of the El Hierro eruption led to confusion amongst the authorities concerning their petrological significance (cf. Carracedo et al. 2012a, 2015; Perez-Torrado et al. 2012). Xeno-pumice fragments were viewed as possibly representing high-silica magma, which might have indicated an imminent explosive eruption (Meletlidis et al. 2012; Sigmarsson et al. 2013). However, the eruption remained purely effusive and relatively minor, and the initial concerns regarding explosive eruptive potential seemed unsubstantiated, at least in hindsight (Carracedo et al. 2015). The uncertainties associated with xeno-pumice during the 2011 eruption therefore highlight

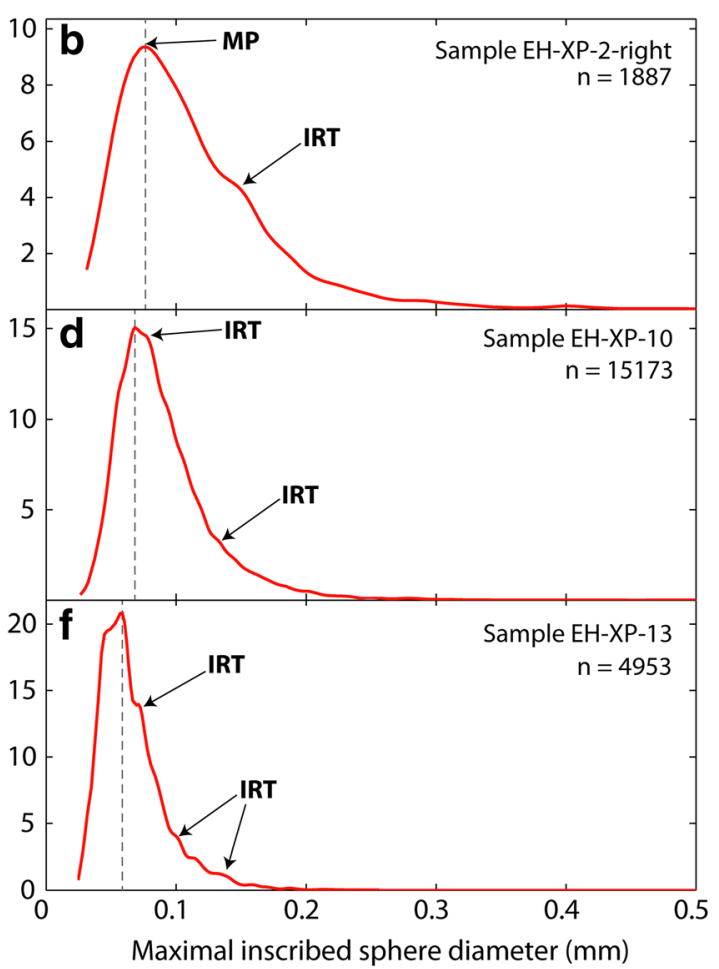

bumpy tails throughout (irregularities in tail (IRT)). We interpret the VSD trends to result from a major degassing pulse superimposed by smaller degassing pulses. Low density data at $>0.5 \mathrm{~mm}$ vesicle diameter are not presented 
the need to better understand the xeno-pumice phenomenon in general and to increase the knowledge-base on potential eruptive products for future Canary eruptions. In this context, our 3D-textural observations on El Hierro xeno-pumice samples reveal snapshots of their vesiculation histories that were frozen in on contact with seawater, and which will likely help us to unravel their ultimate origin.

\section{Vesicle textures in El Hierro xeno-pumice}

All El Hierro xeno-pumice samples investigated here show high-porosity and textural evidence of vesicle interaction and coalescence (Fig. 3). The initial stages of vesicle interaction are documented by small vesicles that frequently surround the larger ones as a result of the internal pressure differential between the differently sized vesicles, which causes a diffusive exchange of volatiles (Ostwald ripening, cf. Cashman and Mangan 1994). More advanced stages of vesicle coalescence and subsequent quenching are recorded by remnant plateau borders and incomplete vesicle wall retraction following a rupture event (cf. Cashman and Mangan 1994; Liu and Zhang 2000). Intense vesicle interaction prior to quenching is evidenced by the observed dominance of spherical vesicle shapes amongst larger vesicles in particular, which is promoted by coalescence under a continuous supply of volatiles (cf. Liu and Zhang 2000; Masotta et al. 2014).

In addition, labelling analyses in Pore $3 D$, which distinguishes vesicle volumes that are connected from isolated ones, confirm that the majority of the vesicles in our samples are connected into a single volume, where gas could move freely within the system (Fig. 3, Supplementary Table 2). Vesicle coalescence and interaction essentially contribute to the development of permeable vesicle networks that define the channels for the migration of volatiles from xeno-pumice into the host basanite magma (Fig. 3h, i, cf. Saar and Manga 1999; Polacci et al. 2008; Okumura et al. 2009). In addition to the connected vesicle volumes, varying amounts of coexisting isolated vesicles are present that do not contribute to the permeability of the rock (Fig. 3, Supplementary Table 2). These isolated vesicle volumes that generally have preserved spherical vesicle shapes, likely testify to a late stage of magma degassing at the vent before eruption, followed by rapid cooling that halted the vesiculation process (cf. Saar and Manga 1999). We therefore infer that xeno-pumice vesicularities capture the instant just prior to chilling against seawater.

\section{Xeno-pumice vesicle size distributions (VSDs)}

VSDs in rocks reflect the processes that gave rise to vesicle size variations, e.g. single or multiple nucleation events, degree of coalescence, and continuous or discontinuous growth (e.g. Klug and Cashman 1994; Klug et al. 2002; Shea et al. 2010). In the simplest sense, each mode in a VSD diagram represents a distinct vesicle population that evolves from a temporally constrained nucleation event, while later coalescence tends to positively skew the data towards larger vesicle diameters and may occasionally form a separate mode (e.g. Cashman and Mangan 1994; Blower et al. 2002; Shea et al. 2010; Toramaru 2014). Multiple modes in VSD diagrams can thus be produced by either secondary nucleation events or vesicle coalescence, or by a combination of both (e.g. Bai et al. 2008; Polacci et al. 2009). These two processes are generally distinguished by the principle that secondary nucleation would produce a higher number density of small bubbles, whereas coalescence would produce a higher number density of larger bubbles (Toramaru 2014). We observe a high number density of small matrix bubbles $(<100 \mu \mathrm{m})$ in the El Hierro xeno-pumice and a progressively lower number density for large vesicles. This suggests the involvement of several superimposed vesicle generations or pulses rather than successive growth and coalescence of a single vesicle population (cf. Meletlidis et al. 2012; Sigmarsson et al. 2013). This notion is furthermore supported by recurring irregularities on the VSD curves (Fig. 4), which likely represent smaller degassing pulses (cf. Blythe et al. 2015). These pulses are best explained by diverse volatile sources in the protolith, which in the case of a siliciclastic sedimentary protolith might represent e.g. pore water and mineral water bound in a range of hydrous mineral phases (e.g. micas or clays).

Notably, the frequently observed vesicle concentration and growth at the margins of relict crystals and rock fragments in our samples shows that crystal breakdown indeed contributed a significant fraction of volatiles to the xeno-pumice texture (Fig. 3b, g, h, see also Carracedo et al. 2015). Many of the relict crystals are quartz grains, as well as occasional phyllosilicates, gypsum, jasper, barite or halite (Troll et al. 2012; Rodriguez-Losada et al. 2015), consistent with $\mathrm{H}_{2} \mathrm{O}$, $\mathrm{CO}_{2}, \mathrm{CH}_{4}$ and $\mathrm{SO}_{2}$ liberation from hydrous phases, evaporate minerals, calcareous and organic components, and with carbon oxides and $\mathrm{H}_{2} \mathrm{O}$ from degassing quartz grains (cf. Vasiloi et al. 1985; Kendrick et al. 2006; Aarnes et al. 2011). Moreover, the vesicle concentration textures we recorded around relict sedimentary fragments and crystals are virtually identical to textures that have been derived from experiments where quartz was heated to magmatic temperatures. In these experimental studies, quartz degassing created a halo of vesicles that attached to the crystal's solid boundaries (Vasiloi et al. 1985; Kendrick et al. 2006; Cluzel et al. 2008), matching our observations on El Hierro xeno-pumice (Figs. 2c and 3c).

\section{Testing for xeno-pumice origin}

A xenolith that undergoes vesiculation controlled by its pore and mineral volatile content, which can be fairly high in shallow sedimentary materials (Gluyas and Cade 1997), is expected to show pulsed degassing (e.g. Blythe et al. 2015). On the 
other hand, an isolated pocket of crystal-free and compositionally homogeneous felsic magma heated by a basanite magma is expected to degas continuously from a single nucleation event that is then further sustained by decompression (see also Introduction section, e.g. Sigmarsson et al. 2013). The latter scenario would produce a continuous vesicle size distribution with a smooth unimodal VSD curve closely symmetrical around the mean (e.g. Shea et al. 2010). The former scenario, in turn, would lead to a more irregular VSD curve caused by variable volatile contributions from different components in the protolith (cf. Blower et al. 2002; Shea et al. 2010; Toramaru 2014).

Our key observations of (i) highly variable vesicle morphologies (Fig. 3), (ii) concentration of large vesicles around relict crystals and sedimentary fragments in xeno-pumice (Fig. 3b, c), and the (iii) irregular, right-skewed VSD curves (Fig. 4) support the presence of multiple vesicle generations that formed during separate degassing pulses. These textural observations emphasise a rapid, but heterogeneous inflation process, with degassing predicted to be more intense around disintegrating residual volatile-rich rock fragments (Carracedo et al. 2015; Zaczek et al. 2015). Consequently, the irregular vesicle size distribution and the spatial heterogeneity of vesicles within the samples are more consistent with progressive release of volatiles from the various components of a sedimentary protolith rather than from a crystal-free, single-phase magma. The various vesiculation pulses from sedimentary protoliths might then result from the release of various gas mixtures derived from (1) pore fluids, (2) mineral water (e.g. from clays), carbon oxides and methane (e.g. from carbonates and organics), (3) $\mathrm{SO}_{2}$ (e.g. from sulphates and other evaporates) and (4) water and carbon oxides from nominally anhydrous phases (e.g. quartz). In this respect, pore water would likely constitute the first and strongest vesiculation pulse, followed by less intense pulses from the various mineral constituents.

\section{Model for vesiculation of sedimentary derived El Hierro xeno-pumice}

Assuming a water saturated silicic sedimentary protolith for the El Hierro high-silica xeno-pumice samples (e.g. > 4 wt.\% $\mathrm{H}_{2} \mathrm{O}$, cf. Zaczek et al. 2015), pore water devolatilisation will commence on heating. Once $\mathrm{H}_{2} \mathrm{O}$-saturated melting of xenopumice sets in (at $\sim 850{ }^{\circ} \mathrm{C}$ ), mineral degassing will create further vesicle generations (Fig. 5a). Some volatiles would remain structurally bound in restite minerals until the final phase of mineral devolatilisation is initiated (e.g. at ambient basanite temperature, $1150{ }^{\circ} \mathrm{C}$ ) or when a last gasp of mineral bound volatiles is released on final decompression (Fig. 5a, b). Mineral devolatilisation is thus expected to generate small pulses of vesicle nucleation from the various types of mineral constituents present, which is consistent with the VSD curves of the El Hierro xeno-pumice (Fig. 4).

Although degassing of sporadically occurring restite minerals would only contribute a few percent of vesicles to the system, and notably in a spatially random fashion, this late generation of vesicles would tend to grow rapidly due to the additional local supply of volatiles from the minerals, which would promote coalescence with neighbouring vesicles and consequent vesicle expansion (see Figs. $3 c$ and $5 b$ ). This process would result in distinctly large vesicles around dehydrating minerals and fragments $\left(\mathrm{V}_{\text {large }}\right)$, which co-exist with smaller matrix vesicles $\left(\mathrm{V}_{\text {small }}\right.$, see Fig. $\left.3 \mathrm{~b}, \mathrm{c}\right)$. Decompression during xeno-pumice ascent in the conduit would then cause further vesicle expansion, coalescence, wall rupture and vesicle networking. We note, however, that small vesicles in El Hierro xeno-pumice are more often tortuously shaped $\left(\mathrm{V}_{\text {small }}\right)$ and may reflect viscous deformation during conduit flow or rapid growth of large vesicles in their vicinity. Large vesicles, on the other hand, appear to be less affected by shearing and viscous deformation probably because of the continuous supply of volatiles into these larger vesicles and the increasing stiffness of the surrounding melt films that would become strongly volatile depleted and therefore have higher viscosity (Schmincke and Swanson 1967; Spark 1978; Hammer et al. 1999; Fig. 3e).

Pulsed xeno-pumice vesiculation (e.g. Fig. 5b) seems to have caused the xeno-pumice protolith to rapidly increase in porosity, thus promoting volatile percolation through the rock and ultimately into the host magma. Gas loss from xenopumice was then associated with at least partial vesicle contraction and deformation, which reduced vesicularity while permeability probably remained at a similar level (Fig. 5b, Rust and Cashman 2004; Cashman and Sparks 2013).

\section{Interaction of magma with pre-island sedimentary rocks}

Xeno-pumice occurred exclusively during the first week of the El Hierro 2011/2012 eruption, probably as a result of magma migrating laterally through the crust at shallow sub-island levels during the two weeks of shallow unrest prior to the actual eruption (e.g. López et al. 2012; González et al. 2013; Carracedo et al. 2015). The assortment of xeno-pumice textures likely reflects the compositional variability of the Cretaceous to Pliocene pre-island siliciclastic and subsidiary calcareous sediments, as well as variable interaction time prior to eruption (cf. Robertson and Stillman 1979a, b; Gee et al. 2001; González et al. 2013; Zaczek et al. 2015). Xeno-pumice vesiculation was then further promoted by depressurisation and the associated decrease in volatile solubility during buoyant rise in the ascending magma (Fig. 5). Shearing along the conduit lining could have caused vesicle distortion, e.g. via pressure shadows (cf. Kennedy et al. 2005), while the dominantly (sub-)spherical shape of the largest vesicles likely 



Fig. 5 a Phase diagram for predicted melting behaviour of $2011 \mathrm{El}$ Hierro xeno-pumice calculated by Perple $X$ (modified after Zaczek et al. 2015). The yellow stars denote successive degassing steps. Pore water likely formed the main volatile source during initial $\mathrm{H}_{2} \mathrm{O}$ saturated melting (1). Subsequently, mineral water was liberated from dehydration melting of hydrous mineral phases (2). Finally, decompression during ascent in the conduit triggered further vesiculation pulses from the melt

and from restite materials (3). b Sequential (pulsed) degassing of xenopumice is schematically summarised in a vesicularity vs. permeability hysteresis (cf. Cashman and Sparks 2013). Steps $i-v$ represent key processes of progressive xeno-pumice evolution during degassing, which is illustrated by $\mathbf{c}$ snapshots of the proposed degassing sequence as recorded in SEM images and 3D tomographs of El Hierro xeno-pumice

argues for continuous bubble growth and inflation during final ascent, i.e. until chilling occurred in seawater. Simultaneously, the high vesicle density and varying size range promoted vesicle coalescence, which, in turn, caused selective growth of large vesicles at the expense of the total vesicle number (e.g.

Masotta et al. 2014). Rapid quenching in seawater upon eruption then halted xeno-pumice vesiculation and a fraction of gas was trapped as isolated vesicles, freezing in the ongoing degassing process before it reached completion (Figs. 3 and 5c, and Supplementary Fig. 2). 


\section{Explosive potential of sedimentary xeno-pumice}

Eruptive products similar to the El Hierro xeno-pumice are known from historic and Holocene volcanic activity in adjacent Canary Islands, but these may not have been fully appreciated at the time of the eruption at El Hierro in 2011 (see Carracedo et al. 2015). For example, sedimentary silica-rich xenoliths with occasional interlayered clay and carbonates, as well as fossil-bearing limestones and shales have been reported from Gran Canaria, La Palma, Lanzarote, Fuerteventura, and from the submarine volcanic edifice of Hijo de Tenerife (e.g. Rothe and Schmincke 1968; Arãna and Ibarrola 1973; Hoernle 1998; Steiner et al. 1998; Klügel et al. 1999; Schmincke and Graf 2000; Hansteen and Toll 2003; Aparicio et al. 2006, 2010). Furthermore, frothy sedimentary xenoliths often tend to occur in association with explosive eruptive events. For instance, xeno-pumice fragments from the 1730-1736 A.D. eruption on Lanzarote are more frequent in the explosive lapilli beds than in the associated lavas (Carracedo et al. 2015). This co-occurrence suggests that a connection between xeno-pumice and locally intensified explosivity may exist, which stresses the need to investigate xeno-pumice in yet more detail.

For instance, sedimentary rocks may maintain porosities up to $20 \mathrm{vol} . \%$ even at several kilometer depth, which provide pore space to host several wt.\% of fluids like e.g. $\mathrm{H}_{2} \mathrm{O}, \mathrm{CO}_{2}$ and hydrocarbons (Gluyas and Cade 1997). Consequently, the vesiculation of sedimentary xenoliths has the potential to release additional volatiles into a magmatic system (cf. Carracedo et al. 2015). At these shallow levels in the crust, the released volatiles would contribute directly to the gas output of the eruption, as the volatiles would not likely be reabsorbed by the melt (cf. Holloway and Blank 1994). This realisation could help explain the phenomenon of phreatomagmatic eruptions in otherwise arid areas of the archipelago (e.g. Clarke et al. 2009), as extra volatiles would be progressively liberated into the magma during conduit ascent, perhaps analogous to an effervescent tablet in water. Hence, xeno-pumice may have the potential to temporarily increase the intensity of an eruption by shifting eruptive behaviour towards a more phreatomagmatic character.

\section{Summary}

Based on our observations of (i) highly variable vesicle morphologies, (ii) concentration of large vesicles at crystal boundaries and sedimentary rock fragments, and (iii) irregularities in right-skewed VSD tails, we argue that the vesiculation history of El Hierro xeno-pumice is best explained by pulsed degassing from a heterogeneous protolith. We conclude that vesicles in xeno-pumice did not form during a single vesiculation event, but instead during several vesiculation pulses.
Although the observed VSD and vesicle shapes do not by themselves rule out a magmatic origin of xeno-pumice, when considered in conjunction with the other available evidence (e.g. sedimentary mineralogy, low trace element concentrations and elevated oxygen isotopes), our data point to a sedimentary origin of El Hierro xeno-pumice. El Hierro xenopumice samples are probably a product of magma-sediment interaction during magma migration through the pre-island oceanic crust prior to eruption. Volatiles contained in sedimentary xenoliths were released on heating to form highly vesicular xeno-pumice, which might have increased the magma's volatile load and temporarily intensified the character of the eruption. These aspects should be considered during future Canary eruptions where xeno-pumice may be amongst the erupted products.

Acknowledgments We thank S. Wiesmaier, A. Klügel, M.-A. Longpré, U. Kueppers, B. Dahrén, L. S. Blythe, T. Hansteen, C. Freda, D. Budd, E. M. Jolis, E. Jonsson, F. C. Meade and K. Zaczek for stimulating discussions on El Hierro xeno-pumice. Extended gratitude also goes to D. Dreossi and N. Sodini for their help during XCT experiments at Elettra. We are grateful to W. Degruyter and an anonymous reviewer for constructive feedback and to J. Gardner for editorial handling of our manuscript. Funding from the European Science Foundation (ESF) through the MeMoVolc research network (Measuring and Modelling of Volcano Eruption Dynamics, www.memovolc.fr), the Spanish program MEC-CGL2011-25494, the Royal Swedish Academy of Sciences (KVA), the Swedish Research Council (VR) and the Centre of Natural Disaster Science (CNDS) at Uppsala University is gratefully acknowledged.

Open Access This article is distributed under the terms of the Creative Commons Attribution 4.0 International License (http:// creativecommons.org/licenses/by/4.0/), which permits unrestricted use, distribution, and reproduction in any medium, provided you give appropriate credit to the original author(s) and the source, provide a link to the Creative Commons license, and indicate if changes were made.

\section{References}

Aarnes I, Fristad K, Planke S, Svensen H (2011) The impact of host-rock composition on devolatilization of sedimentary rocks during contact metamorphism around magic sheet intrusions. Geochem Geophys Geosyst 12(10):Q10019

Abramoff MD, Magelhaes PJ, Ram SJ (2004) Image processing with Image J. Biophoton Int 11(7):36-42

Aparicio A, Bustillo MA, Garcia R, Araña V (2006) Metasedimentary xenoliths in the lavas of the Timanfaya eruption (1730-1736, Lanzarote, Canary Islands): metamorphism and contamination processes. Geol Mag 143(02):181-193

Aparicio A, Tassinari CCG, Garcia R, Araña V (2010) Sr and Nd isotope composition of the metamorphic, sedimentary and ultramafic xenoliths of Lanzarote (Canary Islands): implications for magma sources. J Volcanol Geotherm Res 189(1):143-150

Arãna V, Ibarrola E (1973) Rhyolitic pumice in the basaltic pyroclasts from the 1971 eruption of Teneguía volcano, Canary Islands. Lithos 6(3):273-278 
Bai L, Baker DR, Rivers M (2008) Experimental study of bubble growth in Stromboli basalt melts at 1 atm. Earth Planet Sci Lett 267(3):533547

Baker DR, Brun F, O'Shaughnessy C, Mancini L, Fife JL, Rivers M (2012) A four-dimensional X-ray tomographic microscopy study of bubble growth in basaltic foam. Nat Commun 3:1135

Blower JD, Keating JP, Mader HM, Phillips JC (2002) The evolution of bubble size distributions in volcanic eruptions. J Volcanol Geotherm Res 120(1):1-23

Blythe LS, Deegan FM, Freda C, Jolis EM, Masotta M, Misiti V, Troll VR (2015) $\mathrm{CO}_{2}$ bubble generation and migration during magmacarbonate interaction. Contrib Mineral Petrol 169(4):1-16

Brun F (2012) Development of algorithms and methods for threedimensional image analysis and biomedical applications. Dissertation, University of Trieste (Italy)

Brun F, Dreossi D (2010) Efficient curve-skeleton computation for the analysis of biomedical 3D images. Biomed Sci Instrum 46:475-480

Brun F, Mancini L, Kasae P, Favretto S, Dreossi D, Tromba G (2010) Pore3D: a software library for quantitative analysis of porous media. Nuclear Instruments and Methods in: Physics Research, Section A: Accelerators, Spectrometers, Detectors, and Associated Equipment 615(3):326-332

Carracedo JC, Rodríguez-Badiola E, Guillou H, Nuez JDL, Pérez Torrado FJ (2001) Geology and volcanology of the western Canaries: La Palma and El Hierro. Estud Geol 57:171-295

Carracedo JC, Torrado FP, González AR, Soler V, Turiel JLF, Troll VR, Wiesmaier S (2012a) The 2011 submarine volcanic eruption in El Hierro (Canary Islands). Geol Today 28(2):53-58

Carracedo JC, Pérez-Torrado FJ, Rodríguez-González A, FernandezTuriel JL, Klügel A, Troll VR, Wiesmaier S (2012b) The ongoing volcanic eruption of El Hierro, Canary Islands. Eos-Trans Am Geophys Union 93(2):89-90

Carracedo JC, Troll VR, Zaczek K, Rodriguez-Gonzales A, Vicente S, Deegan FM (2015) The 2011-2012 submarine eruption off El Hierro, Canary Islands: new lessons in oceanic island growth and volcanic crisis management. Earth Sci Rev 150:168-200

Cashman KV, Mangan MT (1994) Physical aspects of magmatic degassing II. Constraints on vesiculation processes from textural studies of eruptive products. In: Carroll MR, Holloway JR (eds) Volatiles in magmas. Rev Mineral Geochem 30(1):447-478

Cashman KV, Sparks RSJ (2013) How volcanoes work: a 25 year perspective. Geol Soc Am Bull 125(5-6):664-690

Clarke H, Troll VR, Carracedo JC (2009) Phreatomagmatic to strombolian eruptive activity of basaltic cinder cones: Montana Los Erales, Tenerife, Canary Islands. J Volcanol Geotherm Res 180(2):225-245

Cloetens P, Barrett R, Baruchel J, Guigay JP, Schlenker M (1996) Phase objects in synchrotron radiation hard X-ray imaging. J Physics D: Applied Physics 29(1):133-146

Cluzel N, Laporte D, Provost A, Kannewisher I (2008) Kinetics of heterogeneous bubble nucleation in rhyolitic melts: implications for the number density of bubbles in volcanic conduits and for pumice textures. Contrib Mineral Petrol 156(6):745-763

Degruyter W, Bachmann O, Burgisser A (2010) Controls on magma permeability in the volcanic conduit during the climactic phase of the Kos Plateau Tuff eruption (Aegean Arc). Bull Volcanol 72(1): 63-74

Del Moro S, Di Roberto A, Meletlidis S, Pompilio M, Bertagnini A, Agostini S, Ridolfi F, Renzulli A (2015) Xenopumice erupted on 15 October 2011 offshore of El Hierro (Canary Islands): a subvolcanic snapshot of magmatic, hydrothermal and pyrometamorphic processes. Bull Volcanol 77(6):1-19

Feldkamp L, Davis L, Kress J (1984) Practical cone-beam algorithm. J Opt Soc Am A 1(6):612-619
Gee MJR, Masson DG, Watts AB, Mitchell NC (2001) Offshore continuation of volcanic rift zones, El Hierro, Canary Islands. J Volcanol Geotherm Res 105(1):107-119

Geldmacher J, Hoernle K, Van den Bogaard P, Duggen S, Werner R (2005) New ${ }^{40} \mathrm{Ar}{ }^{39} \mathrm{Ar}$ age and geochemical data from seamounts in the Canary and Madeira volcanic provinces: support for the mantle plume hypothesis. Earth Planet Sci Lett 237(1):85-101

Giachetti T, Burgisser A, Arbaret L, Druitt TH, Kelfoun K (2011) Quantitative textural analysis of Vulcanian pyroclasts (Montserrat) using multi-scale X-ray computed microtomography: comparison with results from 2D image analysis. Bull Volcanol 73(9):12951309

Gluyas J, Cade CA (1997) Predictions of porosity in compacted sands. In: Kupecz JA, Gluyas J, Bloch S (eds) Reservoir quality prediction in sandstones and carbonates, vol 69. AAPG Memoir, pp. 19-28

González PJ, Samsonov SV, Pepe S, Tiampo KF, Tizzani P, Casu F, Fernández J, Camacho AG, Sansosti E (2013) Magma storage and migration associated with the 2011-2012 El Hierro eruption: implications for crustal magmatic systems at oceanic island volcanoes. J Geophys Res-Sol Ea 118(8):4361-4377. doi:10.1002/jgrb.50289

Guillou H, Carracedo JC, Pérez-Torrado F, Rodríguez Badiola E (1996) $\mathrm{K}-\mathrm{Ar}$ ages and magnetic stratigraphy of a hotspot-induced, fastgrown oceanic island: El Hierro, Canary Islands. J Volcanol Geotherm Res 73(1):141-155

Hammer JE, Cashman KV, Hoblitt RP, Newman S (1999) Degassing and microlite crystallization during pre-climactic events of the 1991 eruption of Mt. Pinatubo, Philippines. Bull Volcanol 60(5):355-380

Hansteen TH, Toll VR (2003) Oxygen isotope composition of xenoliths from the oceanic crust and volcanic edifice beneath Gran Canaria (Canary Islands): consequences for crustal contamination of ascending magmas. Chem Geol 193(3):181-193

Hildebrand T, Rüegsegger P (1997) A new method for the model independent assessment of thickness in three-dimensional images. J Microsc 185(1):67-75

Hoernle K (1998) Geochemistry of Jurassic oceanic crust beneath Gran Canaria (Canary Islands): implications for crustal recycling and assimilation. J Petrol 39(5):859-880

Holloway JR, Blank JG (1994) Application of experimental results to CO-H species in natural melts. Rev Mineral Geochem 30:187-230

Kak AC, Slaney M (1988) Principles of computerized tomographic imaging. IEEE PRESS, New York

Kendrick MA, Phillips D, Miller JML (2006) Part I. Decrepitation and degassing behaviour of quartz up to $1560^{\circ} \mathrm{C}$ : analysis of noble gases and halogens in complex fluid inclusion assemblages. Geochim Cosmochim Ac 70(10):2540-2561

Kennedy B, Spieler O, Scheu B, Kueppers U, Taddeucci J, Dingwell DB (2005) Conduit implosion during Vulcanian eruptions. Geology 33(7):581-584

Ketcham RA, Carlson WD (2001) Acquisition, optimization and interpretation of X-ray computed tomographic imagery: applications to the geosciences. Comput Geosci 27(4):381-400

Klug C, Cashman KV (1994) Vesiculation of May 18, 1980, Mount St. Helens magma. Geology 22(5):468-472

Klug C, Cashman K, Bacon C (2002) Structure and physical characteristics of pumice from the climactic eruption of Mount Mazama (Crater Lake), Oregon. Bull Volcanol 64(7):486-501

Klügel A, Schmincke H-U, White JDL, Hoernle KA (1999) Chronology and volcanology of the 1949 multi-vent rift-zone eruption on la Palma (Canary Islands). J Volcanol Geotherm Res 94(1):267-282

Kueppers U, Nichols ARL, Zanon V, Potuzak M, Pacheco JMR (2012) Lava balloons-peculiar products of basaltic submarine eruptions. Bull Volcanol 74(6):1379-1393

Lindquist WB, Lee SM (1996) Medial axis analysis of void structure in three-dimensional tomographic images of porous media. J Geophys Res-Sol Ea 101(B4):8297-8310 
Liu Y, Zhang Y (2000) Bubble growth in rhyolitic melt. Earth Planet Sci Lett 181(1):251-264

López C, Blanco MJ, Abella R, Brenes B, Cabrera Rodríguez VM, Domínguez CB, Cerdeña I, Felpeto A, Fernández de Villalta M, del Fresno C, García O, García-Arias MJ, García-Cañada L, Gomis Moreno A, González-Alonso E, Guzmán Pérez J, Iribarren I, LópezDíaz R, Luengo-Oroz N, Meletlidis S, Moreno M, Moure D, Pereda de Pablo J, Rodero E, Romero E, Sainz-Maza S, Sentre Domingo MA, Torres PA, Trigo P, Villasante-Marcos V (2012) Monitoring the volcanic unrest of El Hierro (Canary Islands) before the onset of the 2011-2012 submarine eruption. Geophys Res Lett 39(13):L13303

Mangan MT, Cashman KV (1996) The structure of basaltic scoria and reticulite and inferences for vesiculation, foam formation, and fragmentation in lava fountains. J Volcanol Geotherm Res 73(1):1-18

Martí J, Castro A, Rodríguez C, Costa F, Carrasquilla S, Pedreira R, Bolos X (2013) Correlation of magma evolution and geophysical monitoring during the 2011-2012 El Hierro (Canary Islands) submarine eruption. J Petrol 54(7):1349-1373

Masotta M, Ni H, Keppler H (2014) In situ observations of bubble growth in basaltic, andesitic and rhyodacitic melts. Contrib Mineral Petrol 167(2):1-14

Meletlidis S, Di Roberto A, Pompilio M, Bertagnini A, Iribarren I, Felpeto A, Torres PA, D'Oriano C (2012) Xenopumices from the 2011-2012 submarine eruption of El Hierro (Canary Islands, Spain): constraints on the plumbing system and magma ascent. Geophys Res Lett 39(17):L17302. doi:10.1029/2012GL052675

Montanari F (2003) SYRMEP TOMO PROJECT tutorial. Internet report, Sincrotrone Trieste

Okumura S, Nakamura M, Takeuchi S, Tsuchiyama A, Nakano T, Uesugi K (2009) Magma deformation may induce non-explosive volcanism via degassing through bubble networks. Earth Planet Sci Lett 281(3):267-274

Perez-Torrado FJ, Carracedo JC, Rodríguez-González A, Soler V, Troll VR, Wiesmaier S (2012) The submarine eruption of La Restinga (El Hierro, Canary Islands):October 2011- March 2012. Estud Geol 68: $5-27$

Perona P, Malik J (1990) Scale space and edge detection using anisotropic diffusion. IEEE Trans Pattern Anal Mach Intell 12(7):629-639

Polacci M, Baker DR, Mancini L, Tromba G, Zanini F (2006) Threedimensional investigation of volcanic textures by X-ray microtomography and implications for conduit processes. Geophys Res Lett 33(13):L13312

Polacci M, Baker DR, Bai L, Mancini L (2008) Large vesicles record pathways of degassing at basaltic volcanoes. Bull Volcanol 70(9): 1023-1029

Polacci M, Baker DR, Mancini L, Favretto S, Hill RJ (2009) Vesiculation in magmas from Stromboli and implications for normal Strombolian activity and paroxysmal explosions in basaltic systems. J Geophys Res-Sol Ea 114(B1)

Polacci M, Mancini L, Baker DR (2010) The contribution of synchrotron $\mathrm{X}$-ray computed microtomography to understanding volcanic processes. J Synchrotron Radiat 17(2):215-221

Robertson AHF, Stillman CJ (1979a) Late Mesozoic sedimentary rocks of Fuerteventura, Canary Islands: implications for West African continental margin evolution. J Geol Soc 136(1):47-60

Robertson AHF, Stillman CJ (1979b) Submarine volcanic and associated sedimentary rocks of the Fuerteventura Basal Complex, Canary Islands. Geol Mag 116(3):203-214

Rodriguez-Losada JA, Eff-Darwich A, Hernandez LE, Viñas R, Pérez N, Hernandez P, Melian G, Martínez-Frias J, Romero-Ruiz CM, Coello-Bravo JJ (2015) Petrological and geochemical highlights in the floating fragments of the. October 2011 submarine eruption offshore El Hierro (Canary Islands): relevance of submarine hydrothermal processes. J Afr Earth Sci 102:41-49

Rothe P, Schmincke H-U (1968) Contrasting origins of the eastern and western islands of the Canarian archipelago. Nature 218:1152-1154
Rust AC, Cashman KV (2004) Permeability of vesicular silicic magma: inertial and hysteresis effects. Earth Planet Sci Lett 228(1):93-107

Saar MO, Manga M (1999) Permeability-porosity relationship in vesicular basalts. J Geophys Res Lett 26(1):111-114

Savin SM, Epstein S (1970) The oxygen and hydrogen isotope geochemistry of ocean sediments and shales. Geochim Cosmochim Ac 34(1):43-63

Schmincke H-U, Graf G (2000) DECOS/OMEX II, Cruise No. 43. Meteor Reports 1:1-99

Schmincke H-U, Sumita M (2013) Fire in the sea-growth and destruction of submarine volcanoes. Geology 41(3):381-382

Schmincke H-U, Swanson DA (1967) Laminar viscous flowage structures in ash-flow tuffs from Gran Canaria, Canary Islands. J Geol 75(6):641-644

Shea T, Houghton BF, Gurioli L, Cashman KV, Hammer JE, Hobden BJ (2010) Textural studies of vesicles in volcanic rocks: an integrated methodology. J Volcanol Geotherm Res 190(3):271-289

Sigmarsson O, Laporte D, Devouard B, Devidal JL, Carpentier M, Martí J (2013) Formation of U-depleted rhyolite from a basanite at El Hierro, Canary Islands. Contrib Mineral Petrol 165(3):601-622

Soille P (2004) Filtering. In: Morphological image analysis: principles and applications. Springer, Berlin, Heidelberg, pp. 241-265

Song SR, Jones KW, Lindquist WB, Dowd BA, Sahagian DL (2001) Synchrotron X-ray computed microtomography: studies on vesiculated basaltic rocks. Bull Volcanol 63(4):252-263

Spark RSJ (1978) Effect of degassing on rheology of basaltic lava. Nature $276: 385-386$

Steiner C, Hobson A, Favre P, Stampfli GM, Hernandez J (1998) Mesozoic sequence of Fuerteventura (Canary Islands): witness of Early Jurassic sea-floor spreading in the central Atlantic. Geol Soc Am Bull 110(10):1304-1317

Toramaru A (2014) On the second nucleation of bubbles in magmas under sudden decompression. Earth Planet Sci Lett 404:190-199

Troll VR, Schmincke H-U (2002) Magma mixing and crustal recycling recorded in ternary feldspar from compositionally zoned peralkaline ignimbrite 'A', Gran Canaria, Canary Islands. J Petrol 43(2):243-270

Troll VR, Klügel A, Longpré M-A, Burchardt S, Deegan FM, Carracedo JC, Wiesmaier S, Kueppers U, Dahren B, Blythe LS, Hansteen T, Freda C, Budd DA, Jolis EM, Jonsson E, Meade F, Berg S, Mancini L, Polacci M (2012) Floating stones off El Hierro, Canary Islands: xenoliths of pre-island sedimentary origin in the early products of the October 2011 eruption. Solid Earth 3(1):97-11

Troll VR, Deegan FM, Burchardt S, Zaczek K, Carracedo JC, Meade FC, Soler V, Cachao M, Ferreira J, Barker AK (2015) Nannofossils: the smoking gun for the Canarian hotspot. Geol Today 31(4):137-145

Tromba G, Longo R, Abrami A, Arfelli F, Astolfo A, Bregant P, Brun F, Casarin K, Chenda V, Dreossi D, Hola M, Kaiser J, Mancini L, Menk RH, Quai E, Quaia E, Rigon L, Rokvic T, Sodini N, Sanabor D, Schultke E, Tonutti M, Vascotto A, Zanconati F, Cova M, Castelli E (2010) The SYRMEP beamline of Elettra: clinical mammography and bio-medical applications. AIP Conference Proceedings 1266(1):18-23

Vasiloi YV, Kornev VV, Sochivkin GM, Khotimchenko VS (1985) Degassing of granulated vein quartz. Glas Ceram 42(4):187-189

Von Rad U, Einsele G (1980) Mesozoic-Cainozoic subsidence history and palaeobathymetry of the northwest African continental margin (Aaiun Basin to DSDP site 397). Philosophical Transactions of the Royal Society of London A: Mathematical, Physical and Engineering Sciences 294(1409):37-50

Zaczek K, Troll VR, Cachao M, Ferreira J, Deegan FM, Carracedo JC, Soler V, Meade FC, Burchardt S (2015) Nannofossils in 2011 El Hierro eruptive products reinstate plume model for Canary Islands. Sci Rep 5:7954. doi:10.1038/srep07945

Zandomeneghi D, Voltolini M, Mancini L, Brun F, Dreossi D, Polacci M (2010) Quantitative analysis of X-ray microtomography images of geomaterials: application to volcanic rocks. Geosphere 6(6): 793-804 